\title{
L-Lysine-grafted graphene oxide as an effective adsorbent for the removal of methylene blue and metal ions
}

\author{
Yan Yan $^{1,2}$, Jie Li ${ }^{*}$, Fangbei Kong ${ }^{1,2}$, Kuankuan Jia ${ }^{1,2}$, Shiyu $\mathrm{He}^{1,2}$ \\ and Baorong Wang ${ }^{1,2}$
}

Open Access

\author{
Full Research Paper \\ Address: \\ ${ }^{1}$ College Of Science, North China University of Science and \\ Technology, Tangshan 063000, China, ${ }^{2}$ Engineering Computing and \\ Simulation Innovation Laboratory, North China University of Science \\ and Technology, Tangshan 063000 , China and ${ }^{3}$ Ministry of education \\ key laboratory with modern metallurgical technology, North China \\ University of Science and Technology, Tangshan 63000, China \\ Email: \\ Jie Li* - lijie1346@126.com \\ ${ }^{*}$ Corresponding author \\ Keywords: \\ adsorption; copper $(\mathrm{Cu})$ ions; graphene; isotherms; methylene blue
}

Beilstein J. Nanotechnol. 2017, 8, 2680-2688.

doi:10.3762/bjnano.8.268

Received: 19 September 2017

Accepted: 20 November 2017

Published: 13 December 2017

Associate Editor: A. Gölzhäuser

(c) 2017 Yan et al.; licensee Beilstein-Institut. License and terms: see end of document.

\begin{abstract}
In this paper, novel L-lysine-modified graphene oxide (Lys-GO) was synthesized through amidation. The morphological and structural properties of Lys-GO were characterized using infrared spectrometry, scanning electronic microscopy and X-ray photoelectron spectroscopy. The as-prepared Lys-GO material was systematically investigated in a series of batch adsorption experiments for the removal of methylene blue (MB) and copper ions $\left(\mathrm{Cu}^{2+}\right)$ from wastewater. These results showed that Lys-GO is a bifunctional adsorbent for the removal of dyes and metal ions, and excellent adsorption efficiency was obtained. The maximum adsorption capacities for MB dye and $\mathrm{Cu}^{2+}$ were $1679.1 \mathrm{mg} / \mathrm{g}$ and $186.9 \mathrm{mg} / \mathrm{g}$ at $35^{\circ} \mathrm{C}$, respectively. The kinetics of adsorption followed well the linear pseudo-second-kinetic model. The isotherm results indicated that MB adsorption can be described with the Langmuir isotherm model, while the adsorption of $\mathrm{Cu}^{2+}$ can be described with the Freundlich model. The excellent adsorption capacity indicated that the Lys-GO may be a promising adsorption material for the removal of environmental pollutants.
\end{abstract}

\section{Introduction}

Graphene is a two-dimensional carbon material with honeycomb network and $\mathrm{sp}^{2}$ hybridization. Recently, graphene-based materials have drawn attention because of their huge specific surface area, extraordinary electronic transport properties and unique adsorption properties [1-3]. These materials have important applications in many fields, including physics [4], electrochemistry [5], environmental science [6] and catalysis [7]. For example, a $\mathrm{MoS}_{x} / 3 \mathrm{D}$-graphene hybrid material as an electrode material enhanced the efficiency of hydrogen-producing in a fuel cell [8]. Mo et al. reported reduced graphene oxide covalently functionalized with L-lysine [9], which could be used for the electrochemical recognition of tryptophan (Trp) enantiomers. Reduced graphene oxide as an effective adsorbent can be used for the removal of malachite green dye and metal ions 
[10,11]. A high-performance hydrophilic polyvinylidene fluoride/graphene oxide (PVDF/GO)-lysine composite membrane can be used for sea water desalination and purification [12] However, the strong cohesive interactions of graphene basal planes and edges have also caused some difficulties in attaining its optimal performance. Hence, the functionalization of graphene has been extensively developed to further improve its properties and broaden its potential application, such as loading of organic molecules and metal nanoparticles via covalent or noncovalent binding [13-16].

Recently, functionalized graphene materials have shown great potential as highly efficient absorbers for the treatment of environmental pollutants and wastewater purification [17-19]. However, most of the functionalized graphene materials cannot meet practical needs in treating environmental pollutants because of high cost and low performance. Hence, the adsorption performance of graphene-based materials still needs to be improved and the cost lowered. Some reports showed that oxygen functional groups, vacancy defects and $\pi-\pi$ interactions on the graphene basal planes and edges can enhance the adsorption capacities for pollutants $[3,20]$. We inferred that organic molecules modifying graphene might improve their adsorption capabilities. For instance, Swager et al. reported the surface functionalization of graphene oxide (GO) with malononitrile can increase the solubility in either organic or aqueous environments [21]. However, no practical application for the malononitrile-modified GO was described. Interestingly, Ma et al. reported an polyethyleneimine-functionalized ultra-light graphene aerogel (PFGA) used as an adsorbent for the removal of methyl orange and amaranth in 2017 [22]. The maximum adsorption capacities of PFGA for methyl orange and amaranth were as high as $3059.2 \mathrm{mg} / \mathrm{g}$ and $2043.7 \mathrm{mg} / \mathrm{g}$, respectively. Herein, we inferred that grafting amino groups onto graphene might enhance the performance of graphene materials.

According to this analysis, we tried to synthesize a novel graphene material for the removal of heavy metal ions and organic dyes from wastewater. In 2013, Gao et al. developed an environmentally friendly approach to reduce GO with L-lysine [10], which showed potential applications for the removal of metal ions from wastewater. However, L-lysine failed to be grafted onto the reduced graphene oxide (RGO). Results showed a slightly lower absorbing capacity for copper ions $\left(\mathrm{Cu}^{2+}\right)$.

Herein, L-lysine was attached to the surface of GO by amidation between $-\mathrm{COOH}$ and $-\mathrm{NH}_{2}$ to form Lys-GO. GO is an acidic material, and the basic L-lysine can adjust the acid-base properties of GO. Lys-GO showed excellent adsorption capability for the removal of methylene blue (MB) and $\mathrm{Cu}^{2+}$ from simulated wastewater.

\section{Results and Discussion Characterization of the Lys-GO hybrid}

Firstly, the obtained materials were characterized by FTIR analysis (Figure 1). For $\mathrm{GO}$, aromatic $\mathrm{C}=\mathrm{C}$ and $\mathrm{C}=\mathrm{O}$ stretching vibrations can be clearly seen at ca. 1630 and $1743 \mathrm{~cm}^{-1}$. The strong peaks around 3438 and $1400 \mathrm{~cm}^{-1}$ are ascribed to absorbed water. After L-lysine was grafted onto GO, the $\mathrm{CH} / \mathrm{CH}_{2}$ stretching vibration of the obtained Lys-GO material can be seen at about $2923 \mathrm{~cm}^{-1}$. More significantly, a new peak at $1574 \mathrm{~cm}^{-1}$ indicated $\mathrm{N}-\mathrm{H}$ (amide-II bands). The peaks at 1208,1574 and $836 \mathrm{~cm}^{-1}$ are attributed to characteristic amide bonds $[16,23]$. They are the result of the amidation reaction between the $-\mathrm{COOH}$ groups of $\mathrm{GO}$ and the amine groups of L-lysine. These results indicate that L-lysine has been successfully anchored to the GO sheets.

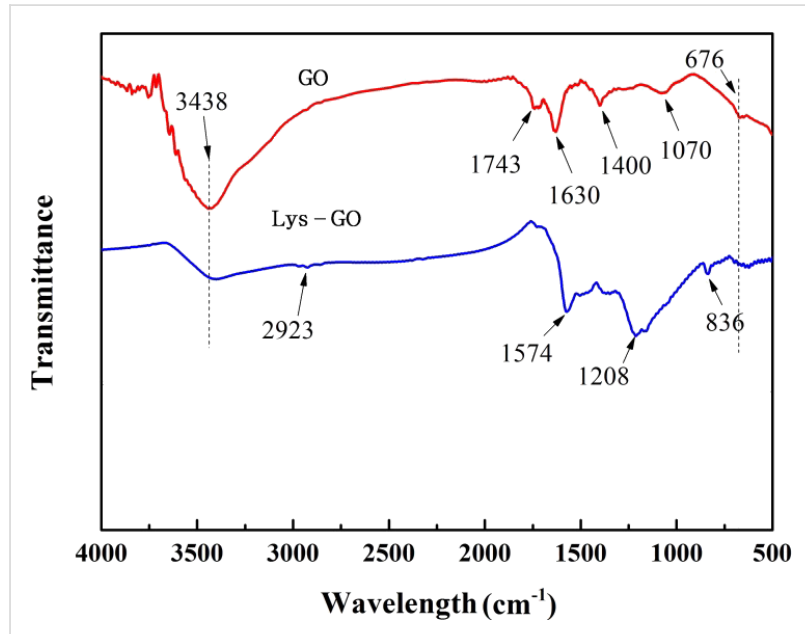

Figure 1: FTIR analysis of the obtained GO and Lys-GO

Next, the chemical states and components of the Lys-GO material were measured by XPS analysis (Figure 2). The full XPS spectrums in the binding energy range of $0-1300 \mathrm{eV}$ of Lys-GO are shown in Figure 2a, which could identify the surface element composition clearly. Only carbon (C 1s), oxygen (O 1s) and nitrogen (N 1s) peaks were recorded in the XPS survey spectrum of Lys-GO. This result illustrated that L-lysine was grafted onto the GO surface successfully. In addition, C 1s, N $1 \mathrm{~s}$ and $\mathrm{O} 1 \mathrm{~s}$ peaks were also analyzed to explain the chemical composition of Lys-GO. The C 1s spectrum of Lys-GO was deconvoluted into five main peaks at 284.6, 285.3, 286.0, 287.9, and $291.2 \mathrm{eV}$ in Figure $2 \mathrm{~b}$, which were attributed to $\mathrm{C}-\mathrm{C} / \mathrm{C}=\mathrm{C}$, $\mathrm{C}-\mathrm{N}, \mathrm{C}-\mathrm{O}, \mathrm{C}=\mathrm{O}$, and $\mathrm{O}-\mathrm{C}=\mathrm{O}$, respectively [24]. The $\mathrm{N} 1 \mathrm{~s}$ spectrum of Lys-GO showed only one peak (Figure 2c), which corresponds to the nitrogen atoms of the amide group $(\mathrm{N}-\mathrm{C}=\mathrm{O})$ at $400.0 \mathrm{eV}$. The $\mathrm{O} 1 \mathrm{~s}$ spectrum was divided into two peaks at $531.6 \mathrm{eV}$ and $533.3 \mathrm{eV}$ (Figure 2d), which indicated different oxygen functional groups in the Lys-GO sample, and repre- 

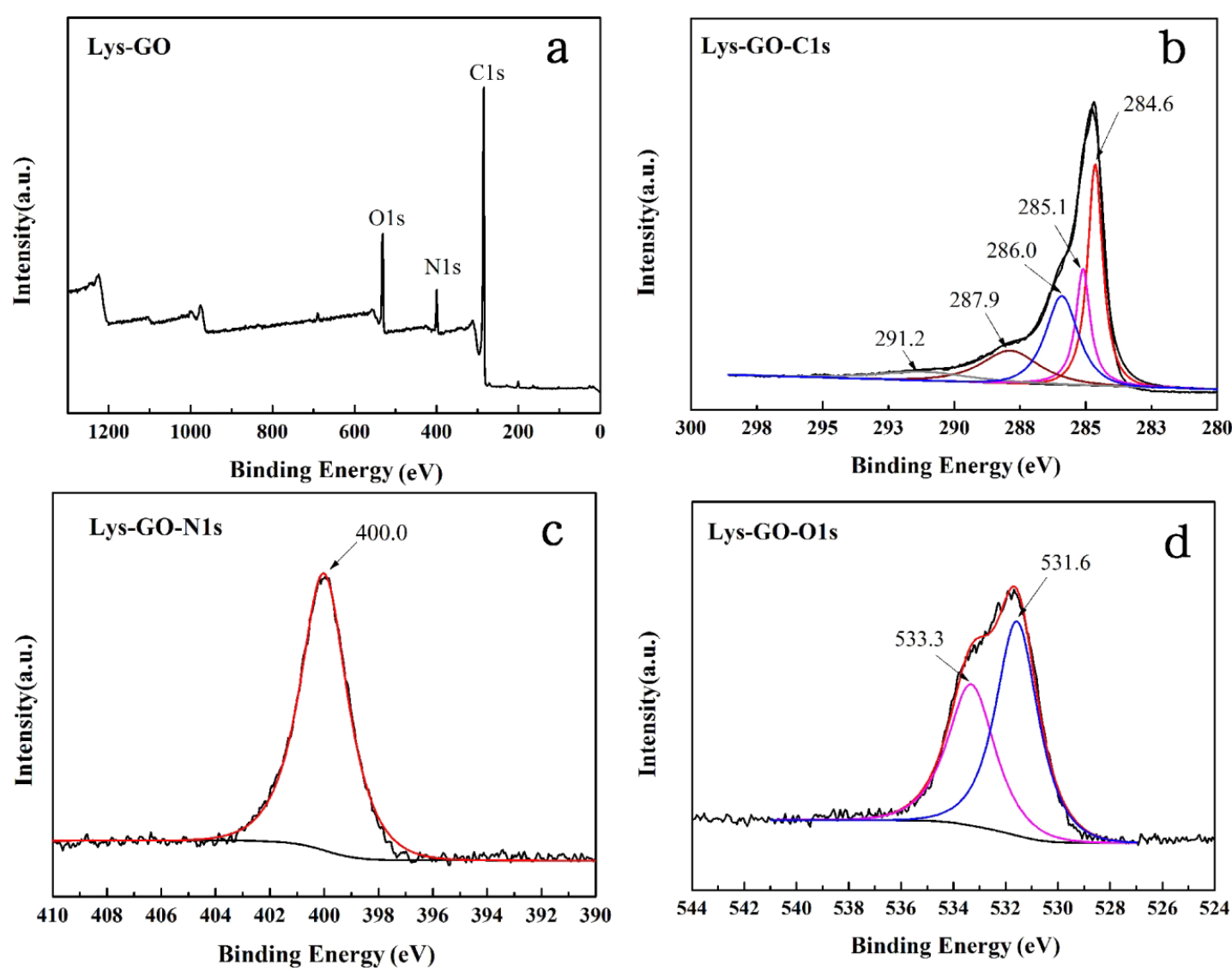

Figure 2: (a) XPS survey spectrum of Lys-GO, (b) C 1s XPS spectrum of Lys-GO, (c) N 1s XPS spectrum of Lys-GO and (d) $O$ 1s spectrum of LysGO.

sented the $\mathrm{O} 1 \mathrm{~s}$ in amide functional group $(\mathrm{N}-\mathrm{C}=\mathrm{O})$ and the hydroxyl group $(\mathrm{C}-\mathrm{OH})$, respectively. These results showed that L-lysine can be easily grafted on the surface of graphene oxide by a simple chemical method. This process is much more economical than other methods, and can be produced on a large scale.
Finally, the morphology of as-prepared graphene materials was characterized by SEM (Figure 3). GO exhibits a structure of the ultra-thin layers with little wrinkles in (Figure 3b). More wrinkled and folded nanosheets of Lys-GO can be clearly seen in Figure $3 \mathrm{a}$. These results showed that the as-prepared Lys-GO may have more vacancy defects and functional groups by the
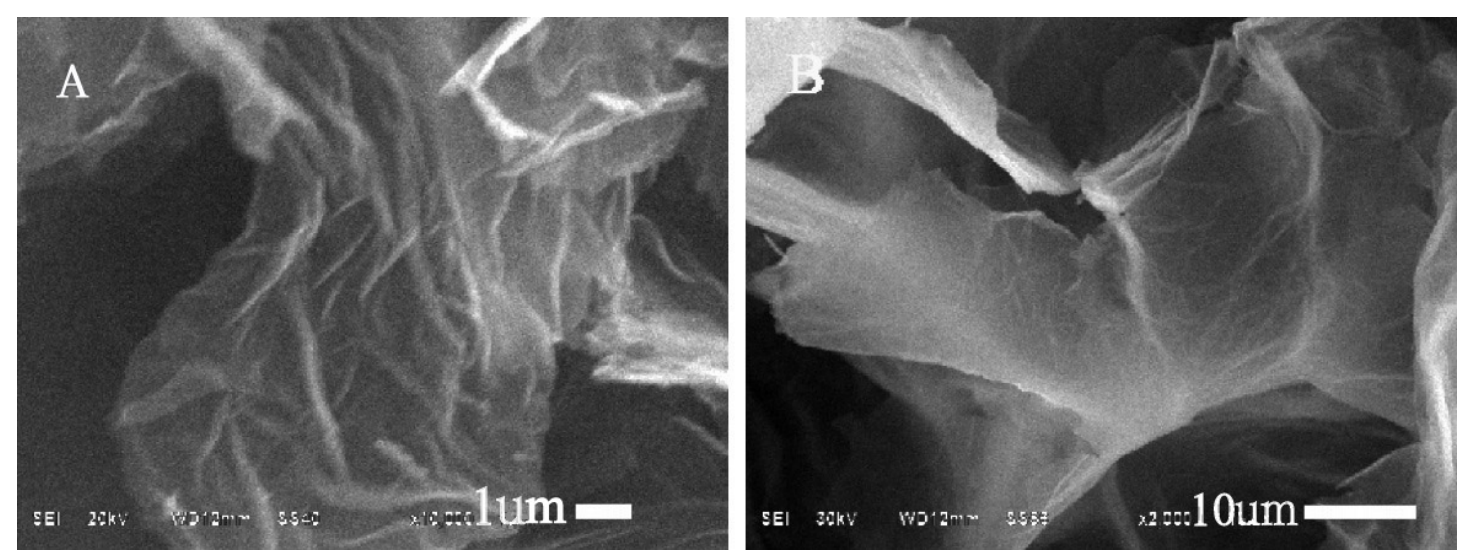

Figure 3: SEM images of Lys-GO (A) and GO (B). 
chemical modification, which may lead to an enhanced performance in the adsorption of pollutants.

\section{Effect of the $\mathrm{pH}$ value on the adsorption of $\mathrm{MB}$ and $\mathrm{Cu}^{2+}$}

In order to identify the adsorption capability of Lys-GO for MB and metal ions, a series of batch adsorption experiments were conducted. First, the effect of the $\mathrm{pH}$ value on $\mathrm{MB}$ and $\mathrm{Cu}^{2+}$ adsorption was studied. The initial $\mathrm{pH}$ value as an important parameter may control the adsorption process, particularly the adsorption capacity, because the adsorption equilibrium changes with different $\mathrm{pH}$ values. Hence, the variation of MB and $\mathrm{Cu}^{2+}$ adsorption on Lys-GO under different $\mathrm{pH}$ conditions was investigated (Figure 4).

The amount of MB adsorbed on Lys-GO increases with increasing $\mathrm{pH}$ values until $\mathrm{pH} 8$ and then decreases again slowly (Figure 4a). For $\mathrm{Cu}^{2+}$, adsorption amount increases with increasing $\mathrm{pH}$ value from $\mathrm{pH} 3$ to $\mathrm{pH} 7$ (Figure $4 \mathrm{~b}$ ). When the $\mathrm{pH}$ value is increased further, the amount of adsorbed $\mathrm{Cu}^{2+}$ is reduced again. The optimal $\mathrm{pH}$ values for the adsorption of $\mathrm{MB}$ and $\mathrm{Cu}^{2+}$ on Lys-GO were 8.0 and 7.0, respectively. The effect of the $\mathrm{pH}$ value on the adsorption of $\mathrm{MB}$ and $\mathrm{Cu}^{2+}$ can be attributed to the form of ionic species in the solutions $[25,26]$. The higher or lower the $\mathrm{pH}$ value, the more anions or cations will exist in the solution, which might be bad for the removal of $\mathrm{MB}$ and $\mathrm{Cu}^{2+}$.

\section{Adsorption kinetics}

To better understand the processes and mechanisms of adsorption, the adsorption kinetics was investigated. In Figure 5, the adsorption of $\mathrm{MB}$ and $\mathrm{Cu}^{2+}$ on Lys-GO as a function of the time at different temperatures are shown.

From Figure 5, it can be observed that the kinetic equilibrium for the adsorption of MB on Lys-GO was reached after $120 \mathrm{~min}$, while that of $\mathrm{Cu}^{2+}$ is reached after $180 \mathrm{~min}$. Moreover, the equilibrium adsorption capacity of $\mathrm{MB}$ and $\mathrm{Cu}^{2+}$ on LysGO increases slightly with the increase of temperature. A similar character can be seen for all curves. The adsorption process is very fast before $50 \mathrm{~min}$, and then slows down until the equilibrium was reached. The whole at $20^{\circ} \mathrm{C}$ can be presented by
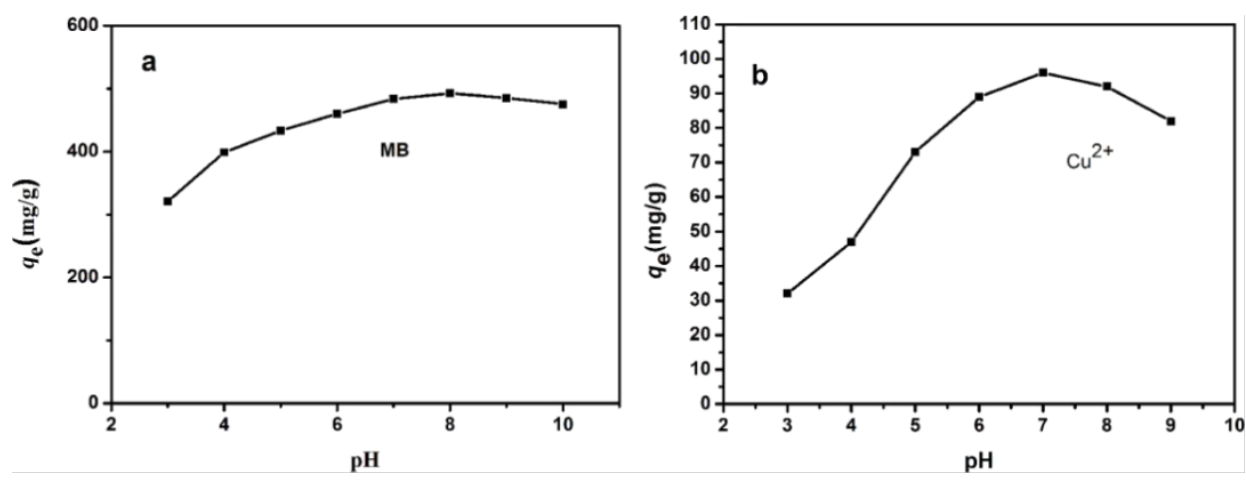

Figure 4: Effect of solution $\mathrm{pH}$ value on the adsorption of $(\mathrm{a}) \mathrm{MB}\left(C_{0}=500 \mathrm{mg} / \mathrm{L}\right)$ and $(\mathrm{b}) \mathrm{Cu}^{2+}\left(C_{0}=100 \mathrm{mg} / \mathrm{L}\right)$ on $\mathrm{Lys}-\mathrm{GO}$.
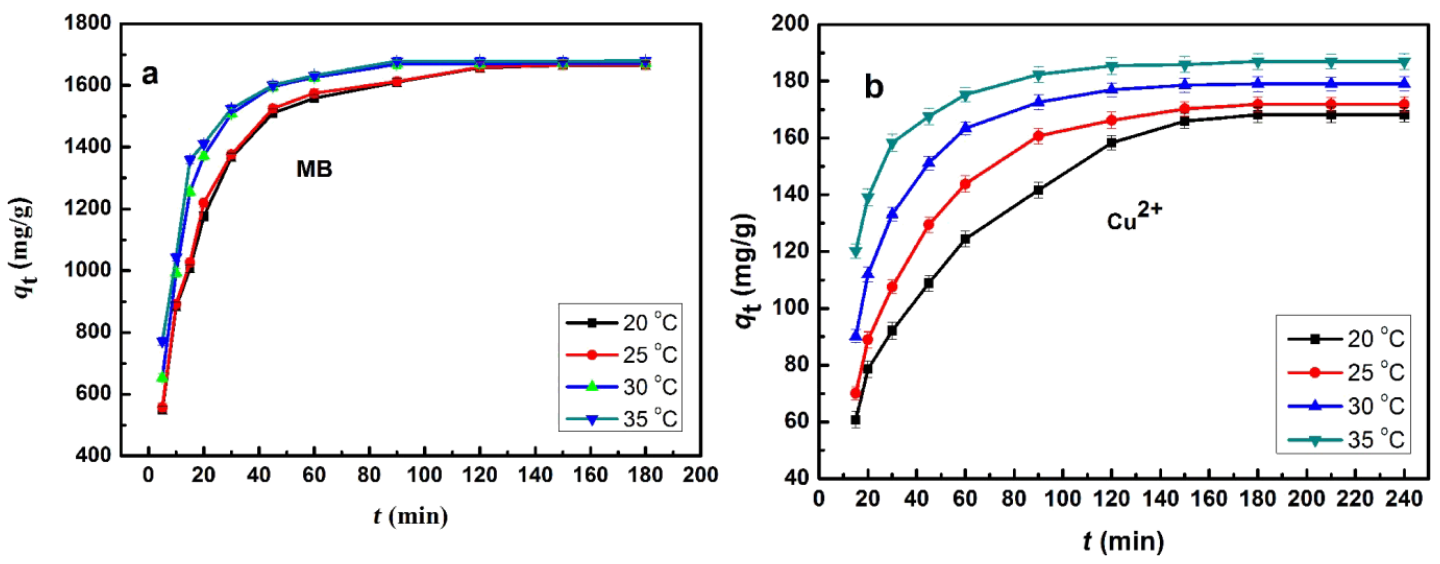

Figure 5: The adsorption of (a) MB $\left(C_{0}=1800 \mathrm{mg} / \mathrm{L}, \mathrm{pH} 8.0\right)$ and $(\mathrm{b}) \mathrm{Cu}^{2+}\left(C_{0}=200 \mathrm{mg} / \mathrm{L}, \mathrm{pH} 7.0\right)$ on Lys-GO. 
the formula: $y=a \cdot \ln (x)+b\left(R^{2}=0.94\right)$. To further investigate the adsorption process, the experimental adsorption kinetic data were analyzed using two conventional kinetic models (linear pseudo-first-order and linear pseudo-second-order).

The linear pseudo-first-order kinetic model can be expressed as:

$$
\ln \left(q_{\mathrm{e}}-q_{\mathrm{t}}\right)=\ln q_{\mathrm{e}}-\kappa_{1} t,
$$

where $q_{e}$ and $q_{\mathrm{t}}$ are the adsorbed amounts $(\mathrm{mg} / \mathrm{g})$ of $\mathrm{MB}$ or $\mathrm{Cu}^{2+}$ at equilibrium and at different times $t$, respectively. $\kappa_{1}$ $\left(\min ^{-1}\right)$ is the rate constant of a pseudo-first-order model of adsorption. The values of $q_{\mathrm{e}}$ and $\kappa_{1}$ can be calculated from the intercept and slope of the linear plot of $\ln \left(q_{\mathrm{e}}-q_{\mathrm{t}}\right)$ as a function of $t$.

The pseudo-second-order model includes all the steps of adsorption including external film diffusion, adsorption, and internal particle diffusion, and can be expressed as:

$$
\frac{t}{q_{\mathrm{t}}}=\frac{1}{\kappa_{2} q_{\mathrm{e}}^{2}}+\frac{t}{q_{\mathrm{e}}},
$$
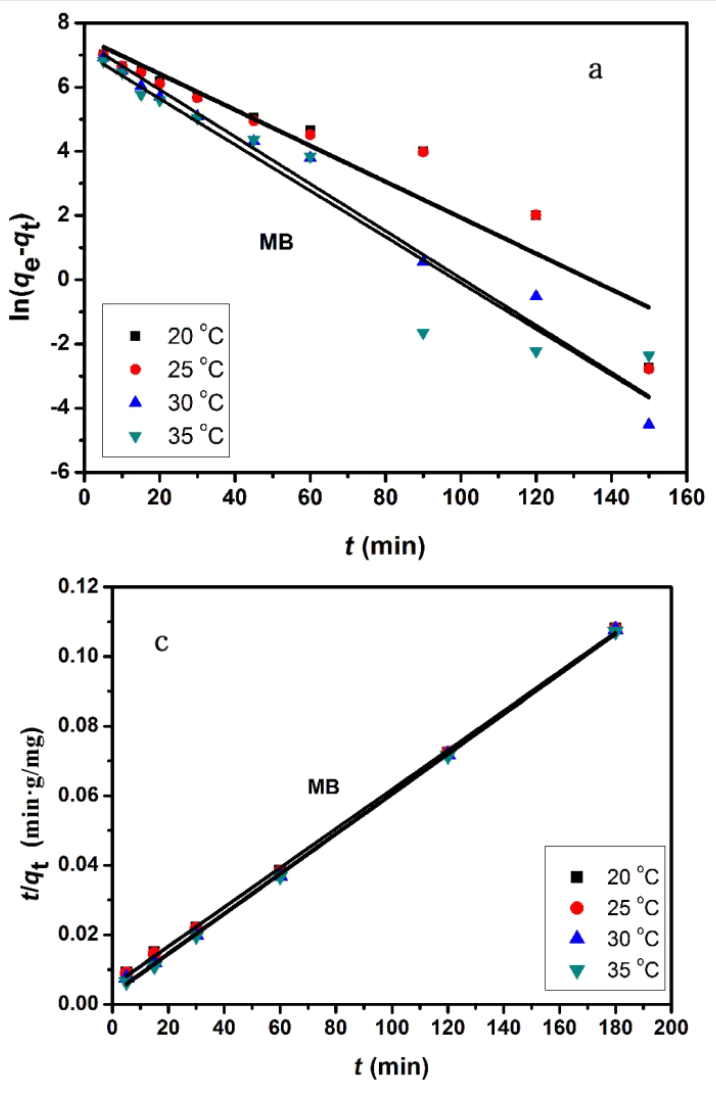

where $q_{\mathrm{e}}$ and $q_{\mathrm{t}}$ are defined as above and $\kappa_{2}$ is the rate constant of the pseudo-second-order model of adsorption $(\mathrm{g} / \mathrm{mg} / \mathrm{min})$. The slope and intercept of the linear plot of $t / q_{\mathrm{t}}$ against $t$ yield the values of $q_{\mathrm{e}}$ and $\kappa_{2}$.

The calculated values of $q_{\mathrm{e}, \mathrm{cal}}, \kappa_{1}, \kappa_{2}$, and $R^{2}$ from Figure 6 are summarized in Table 1. For the adsorption MB on Lys-GO, the correlation coefficient $R^{2}$ for the linear pseudo-second-order model reached up to 0.999 , which is much better than that of the pseudo-first-order model. Addtionally, The values of $q_{\mathrm{e}, \text { cal }}$ were also in accordance with the experimental adsorption capacity ( $q$ e,exp $)$ obtained from the pseudo-second-order model. These results indicated that the pseudo-second-order kinetic model may describe the adsorption of MB on graphene. The adsorption kinetic model of $\mathrm{Cu}^{2+}$ was very similar to that of MB on Lys-GO, and the linear pseudo-second-order kinetic model fitted the adsorption of $\mathrm{Cu}^{2+}$ on Lys-GO.

\section{MB adsorption isotherms}

The adsorption equilibrium isotherm is a key for describing the distribution of the adsorbate molecules between the liquid and the solid phase in equilibrium. Several mathematical models have been widely used to describe equilibrium states of the
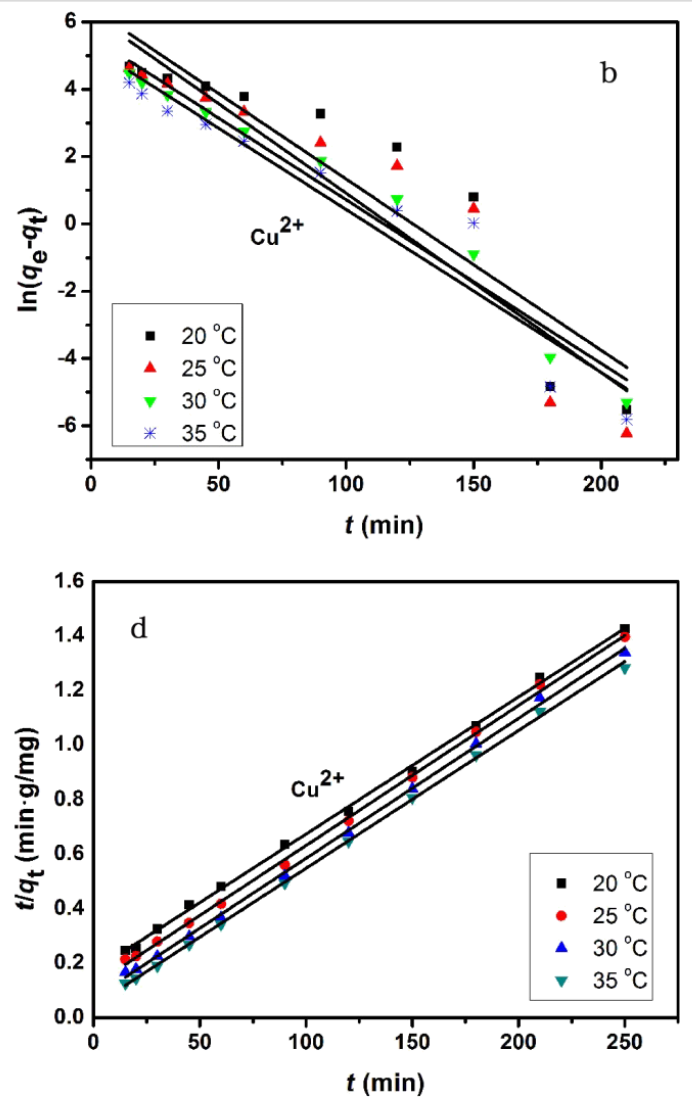

Figure 6: $(a, b)$ Pseudo-first-order and (c,d) pseudo-second-order kinetics models for MB and $\mathrm{Cu}^{2+}$ adsorption on Lys-Go (initial conditions: MB $1800 \mathrm{mg} / \mathrm{L}$, solution $\left.\mathrm{pH} 8.0 ; \mathrm{Cu}^{2+} 200 \mathrm{mg} / \mathrm{L}, \mathrm{pH} 7.0\right)$. 


\begin{tabular}{|c|c|c|c|c|c|c|c|c|}
\hline \multirow[b]{2}{*}{ temperature } & \multirow[b]{2}{*}{$20^{\circ} \mathrm{C}$} & \multicolumn{3}{|c|}{ MB } & \multicolumn{4}{|c|}{$\mathrm{Cu}^{2+}$} \\
\hline & & $25^{\circ} \mathrm{C}$ & $30^{\circ} \mathrm{C}$ & $35^{\circ} \mathrm{C}$ & $20^{\circ} \mathrm{C}$ & $25^{\circ} \mathrm{C}$ & $30^{\circ} \mathrm{C}$ & $35^{\circ} \mathrm{C}$ \\
\hline$q_{e, \exp }(\mathrm{mg} / \mathrm{g})$ & 1664.882 & 1666.358 & 1670.513 & 1679.104 & 168.166 & 171.832 & 179.011 & 186.918 \\
\hline \multicolumn{9}{|c|}{ linear pseudo-first-order } \\
\hline $\mathrm{K}_{1}\left(\mathrm{~min}^{-1}\right)$ & $5.60 \cdot 10^{-2}$ & $5.59 \cdot 10^{-2}$ & $7.34 \cdot 10^{-2}$ & $7.17 \cdot 10^{-2}$ & $5.08 \cdot 10^{-2}$ & $5.33 \cdot 10^{-2}$ & $4.86 \cdot 10^{-2}$ & $4.84 \cdot 10^{-2}$ \\
\hline$q_{\mathrm{e}, \mathrm{cal}}(\mathrm{mg} / \mathrm{g})$ & 1907.789 & 1817.014 & 1620.225 & 1177.619 & 611.106 & 511.563 & 263.757 & 193.234 \\
\hline SD & 5.195 & 4.091 & 2.364 & 7.465 & 7.015 & 6.144 & 3.069 & 0.838 \\
\hline$R^{2}$ & 0.8895 & 0.8882 & 0.9771 & 0.9198 & 0.8445 & 0.8701 & 0.9627 & 0.9134 \\
\hline \multicolumn{9}{|c|}{ Linear pseudo-second-order } \\
\hline $\mathrm{K}_{2}(\mathrm{~g} / \mathrm{mg} / \mathrm{min})$ & $5.82 \cdot 10^{-5}$ & $6.18 \cdot 10^{-5}$ & $1.01 \cdot 10^{-4}$ & $1.20 \cdot 10^{-4}$ & $1.48 \cdot 10^{-4}$ & $2.23 \cdot 10^{-4}$ & $3.67 \cdot 10^{-4}$ & $5.91 \cdot 10^{-4}$ \\
\hline $\mathrm{q}_{\mathrm{e}, \mathrm{cal}}(\mathrm{mg} / \mathrm{g})$ & 1772.801 & 1768.703 & 1740.508 & 1738.680 & 198.807 & 194.553 & 194.932 & 198.020 \\
\hline SD & 3.463 & 3.372 & 2.789 & 2.572 & 1.845 & 1.589 & 1.330 & 1.111 \\
\hline$R^{2}$ & 0.9995 & 0.9994 & 0.9993 & 0.9996 & 0.9987 & 0.9988 & 0.9990 & 0.9993 \\
\hline
\end{tabular}

asD: standard deviation $=\left[\left(q_{e, \text { cal }}-q_{e, e x p}\right) /(n-2)\right]^{1 / 2} ; n$ : number of data points in the set; $\mathrm{k}_{1}$ : rate constant for a pseudo-first-order reaction (min $\left.{ }^{-1}\right)$; $\mathrm{K}_{2}$ : rate constant for a pseudo-second-order reaction $(\mathrm{g} / \mathrm{mg} / \mathrm{min}) ; q_{\mathrm{e}}$ : maximum capacity of adsorption $(\mathrm{mg} / \mathrm{g})$.

adsorption of molecules on surfaces. To the best of our knowledge, most of the adsorption systems were generally analyzed by the models of Langmuir or Freundlich. Therefore, the experimental data were also fitted by Langmuir and Freundlich isotherms in this work.

The Langmuir isothermal linear equation is described as

$$
q_{\mathrm{e}}=\frac{q_{\mathrm{max}} \cdot K_{\mathrm{L}} \cdot C_{\mathrm{e}}}{1+K_{L} \cdot C_{\mathrm{e}}},
$$

and the Freundlich isothermal linear expression is represented by

$$
q_{\mathrm{e}}=K_{\mathrm{F}} \cdot C_{\mathrm{e}}^{1 / n}
$$

where $C_{\mathrm{e}}(\mathrm{mg} / \mathrm{L})$ is the equilibrium concentration of $\mathrm{MB}$ or $\mathrm{Cu}^{2+}$ in solution, $q_{\mathrm{e}}(\mathrm{mg} / \mathrm{g})$ is the amount adsorbed on Lys-GO, $q_{\text {max }}(\mathrm{mg} / \mathrm{g})$ is the maximum monolayer adsorption capacity on Lys-GO, $K_{\mathrm{L}}(\mathrm{L} / \mathrm{mol})$ is a coefficient related to the energy of adsorption and is expected to vary with temperature; $K_{\mathrm{F}}$ $\left(\mathrm{mol}^{(1-n)} \cdot \mathrm{L}^{n} / \mathrm{g}\right)$ and $n$ are constants of the Freundlich isotherm related to the adsorption capacity and adsorption tendency, respectively.

The adsorption isotherms of $\mathrm{MB}$ or $\mathrm{Cu}^{2+}$ on Lys-GO are given in Figure 7. The values of calculated Langmuir constants $\left(K_{\mathrm{L}}\right.$ and $q_{\max }$ ) and Freundlich isotherm constants ( $n$ and $K_{\mathrm{F}}$ ) are listed in Table 2. As seen from Table 2, when the Langmuir model was used to fit the experimental data in Figure 7a, the calculated value the maximum MB adsorption capacity was approximately $1634.36 \mathrm{mg} / \mathrm{g}$, and the determination coefficient
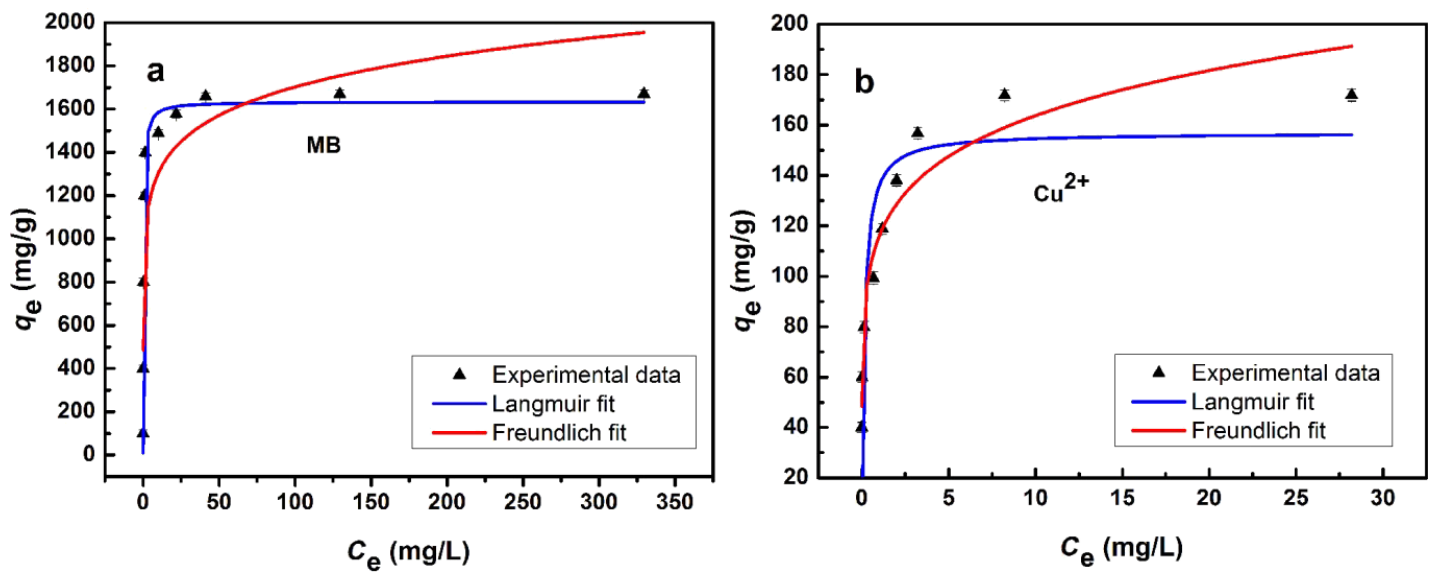

Figure 7: Adsorption isotherms of MB (a) and Cu2+ (b) on Lys-GO. 


\begin{tabular}{|c|c|c|c|c|c|c|}
\hline \multirow[t]{2}{*}{ adsorbate } & \multicolumn{3}{|c|}{ Langmuir } & \multicolumn{3}{|c|}{ Freundlich } \\
\hline & $q_{\max }(\mathrm{mg} / \mathrm{g})$ & $K_{\mathrm{L}}(\mathrm{L} / \mathrm{mol})$ & $R^{2}$ & $n$ & $K_{\mathrm{F}}\left(\mathrm{mol}^{(1-n)} \cdot \mathrm{L}^{\mathrm{n}} / \mathrm{g}\right)$ & $R^{2}$ \\
\hline MB & 1634.362 & 3.23 & 0.9879 & 8.64 & 999.02 & 0.7669 \\
\hline $\mathrm{Cu}^{2+}$ & 156.908 & 6.49 & 0.6722 & 6.67 & 115.90 & 0.9281 \\
\hline
\end{tabular}

$R^{2}=0.9879$. The value of $R^{2}(0.7669)$ obtained from the Freundlich isotherm was much lower than that of the Langmuir isotherm. For the adsorption isotherms of $\mathrm{Cu}^{2+}$ on Lys-GO in Figure $7 \mathrm{~b}$, the calculated value of the maximum $\mathrm{Cu}^{2+}$ adsorption capacity was approximately $156.91 \mathrm{mg} / \mathrm{g}$, and $R^{2}$ was equal to 0.6722 using the Langmuir model. As compared with the Langmuir model, the Freundlich model was more suitable for describing the adsorption equilibrium of $\mathrm{Cu}^{2+}$ on Lys-GO. Similar result of $\mathrm{Cu}^{2+}$ adsorption was reported in $[22,24]$.

The removal of $\mathrm{MB}$ and $\mathrm{Cu}^{2+}$ with the help of other materials has been extensively studied. The adsorption capacities of other adsorbents were compared in Table 3. Obviously, the adsorption performance of Lys-GO for MB and $\mathrm{Cu}^{2+}$ are much better than those of the other previously reported materials. The excellent adsorption performance of Lys-GO might be attributed to two factors: 1) Grafting L-lysine on the GO can improve the affinity for $\mathrm{MB}$ and $\mathrm{Cu}$ ions because more functional groups are available. 2) Strong $\pi-\pi$ interactions and vacancy defects are good for enhancing the adsorption capacity of graphene materials. These results indicated that Lys-GO material has great potential application in treating wastewater.

\section{Conclusion}

A novel amino acid-graphene composite material was synthesized using graphene oxide (GO) and L-lysine. The interfacial property of GO can be improved by the chemical modification.
The as-prepared Lys-GO material as an adsorbent was systematically evaluated with respect to the removal methylene blue (MB) and $\mathrm{Cu}^{2+}$ from simulated wastewater. Compared to $\mathrm{GO}$, the performance and adsorption capacity of the modified LysGO material was significantly improved. The maximum adsorption capacity for $\mathrm{MB}$ and $\mathrm{Cu}^{2+}$ was $1679.1 \mathrm{mg} / \mathrm{g}$ and $186.9 \mathrm{mg} / \mathrm{g}$, respectively. The kinetics of adsorption followed well the linear pseudo-second-kinetic model. For the Lys-GO material, the isotherm results showed that MB adsorption fitted the Langmuir isotherm model, while $\mathrm{Cu}^{2+}$ fitted the Freundlich model. The adsorption capacity of $\mathrm{MB}$ and $\mathrm{Cu}^{2+}$ on Lys-GO prepared from GO was much better than that of other materials, such as GO/MgO NCs or GO with different defects. The functionalized graphene material may be a promising candidate for the removal of environmental pollutants.

\section{Experimental}

\section{Materials and instrumentation}

Graphite powder was purchased from Shanghai Huayi Company (Shanghai, China). $\mathrm{KMnO}_{4}, \mathrm{NaNO}_{3}, \mathrm{H}_{2} \mathrm{SO}_{4}$ (98\%) and $\mathrm{HCl}(36-38 \%)$ were obtained from Sinopharm Chemical Reagent Co. Ltd. (Shanghai China). The deionized (DI) water used throughout all experiments was purified to $18.2 \mathrm{M} \Omega \cdot \mathrm{cm}$ with the Millipore system.

Lys-GO was characterized by scanning electron microscopy (SEM, AJEOL JSM-6510LV, JAPAN) and X-ray photoelec-

\begin{tabular}{|c|c|c|c|}
\hline adsorbate & type of adsorbents & $q_{\max }(\mathrm{mg} / \mathrm{g})$ & reference \\
\hline \multirow[t]{6}{*}{ MB } & Mt-SB12 & 254 & {$[27]$} \\
\hline & agar/graphene oxide (AGO) & 578 & {$[28]$} \\
\hline & graphene oxide/calcium alginate $(\mathrm{GO} / \mathrm{CA})$ & 181.81 & [29] \\
\hline & GO/MgO NCs & 833 & {$[30]$} \\
\hline & magnetic graphene sponge $\left(\mathrm{Fe}_{3} \mathrm{O}_{4}-\mathrm{GS}\right)$ & 526 & [31] \\
\hline & Lys-GO & 1679.1 & this work \\
\hline \multirow[t]{6}{*}{$\mathrm{Cu}^{2+}$} & Mt-SB12 & 10.2 & {$[27]$} \\
\hline & magnetic cassava residue microspheres (MCRS) & 110.5 & [32] \\
\hline & PAN-kapok hollow microtubes & 90.1 & [33] \\
\hline & silico-manganese nanohybrid adsorbent (SMNA) & $40-88$ & [34] \\
\hline & GO1 & 91.6 & [35] \\
\hline & Lys-GO & 186.9 & this work \\
\hline
\end{tabular}


tron spectroscopy (XPS, Kratos XSAM-800, UK). Fouriertransform infrared (FTIR) spectroscopy was performed on a Perkin-Elmer model 2000 FTIR spectrophotometer using the Spectrum v. 2.00 software package. MB solution was analyzed using a UV spectrophotometer (Shimadzu, UV-2550) by monitoring the absorbance changes at the wavelength of maximum absorbance $(664 \mathrm{~nm}) \cdot \mathrm{Cu}^{2+}$ concentration was analyzed using atomic absorption spectrometry at $324.8 \mathrm{~nm}$ (AAanalyst300, Perkin-Elmer).

\section{Synthesis of the Lys-GO hybrid}

Typically, GO $(30 \mathrm{mg})$ was treated with $\mathrm{SOCl}_{2}(20 \mathrm{~mL})$ in the presence of $0.5 \mathrm{~mL}$ of dry $N, N$-dimethylformamide (DMF) in a $50 \mathrm{~mL}$ round-bottomed flask and heated to $70^{\circ} \mathrm{C}$ for $24 \mathrm{~h}$, using an absorption device of neutralization tail gas. After completion of the reaction, the solvent was evaporated at $100{ }^{\circ} \mathrm{C}$ and the solid was washed by anhydrous tetrahydrofuran (THF). The obtained product was reacted with L-lysine $(2.0 \mathrm{mmol})$ in anhydrous DMF $(20 \mathrm{~mL})$ at $90{ }^{\circ} \mathrm{C}$ for $12 \mathrm{~h}$. The L-lysine modified graphene sheets were obtained by filtration and washed by 5 wt $\% \mathrm{NaHCO}_{3}$, deionized water, and ethanol to remove the unreacted amino acids, respectively. Finally, the sample was dried under vacuum at $50{ }^{\circ} \mathrm{C}$. The whole route of synthesis is shown in Scheme 1.

\section{Adsorption kinetics}

The adsorption as a function of the time was studied to obtain the kinetics information. $10 \mathrm{mg}$ absorbent and $10 \mathrm{~mL}$ of $\mathrm{MB}$ or $\mathrm{Cu}^{2+}$ solution of known concentration were transferred in flask and shaken at four different temperatures $(20,25,30$, and $\left.35^{\circ} \mathrm{C}\right)$. The solutions were collected at different time points (5-250 min), and then centrifuged at 12,000 rpm for $10 \mathrm{~min}$. The liquids were analyzed for $\mathrm{MB}$ or $\mathrm{Cu}^{2+}$ concentration measurements. The obtained data in batch mode studies were used to calculate for each sample of $\mathrm{Cu}^{2+}$ or $\mathrm{MB}$ as follows:

$$
q_{\mathrm{e}}=\frac{\left(C_{0}-C_{e}\right) V}{m}
$$

where $q_{\mathrm{e}}$ is the equilibrium adsorption capacity of $\mathrm{Cu}^{2+}$ or $\mathrm{MB}$ on Lys-GO $(\mathrm{mg} / \mathrm{g}), V$ is the sample volume $(\mathrm{L}), C_{0}$ and $C_{\mathrm{e}}$ are the initial and equilibrium concentration of $\mathrm{Cu}^{2+}$ or $\mathrm{MB}(\mathrm{mg} / \mathrm{L})$ respectively, and $m$ is the weight of Lys-GO (g).

\section{Adsorption isotherms}

To quantify the adsorption isotherms, $10 \mathrm{~mL}$ of $\mathrm{MB}$ or $\mathrm{Cu}^{2+}$ solution with different initial concentrations was added to $10 \mathrm{mg}$ Lys-GO, and shaken for $250 \mathrm{~min}$ at $303 \mathrm{~K}$. The supernatant was collected by centrifugation. The concentration of remnant $\mathrm{MB}$ was measured by UV spectrophotometry, referring to a standard curve. The concentration of remnant $\mathrm{Cu}^{2+}$ was analyzed using atomic absorption spectrometry at $324.8 \mathrm{~nm}$.

\section{Acknowledgements}

This work was supported by the National Natural Science Foundation of China (no. 51504080), the National Natural Science Foundation of Hebei Province (no. E2017209178), the Science

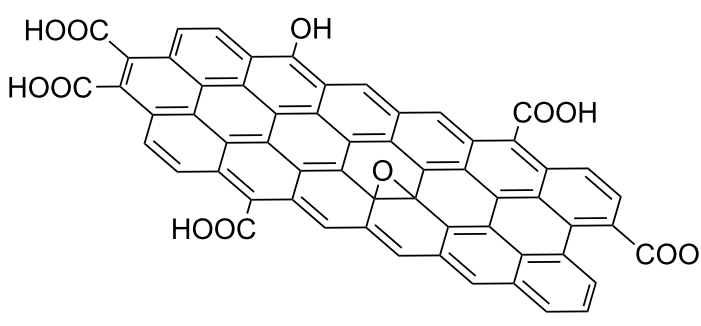

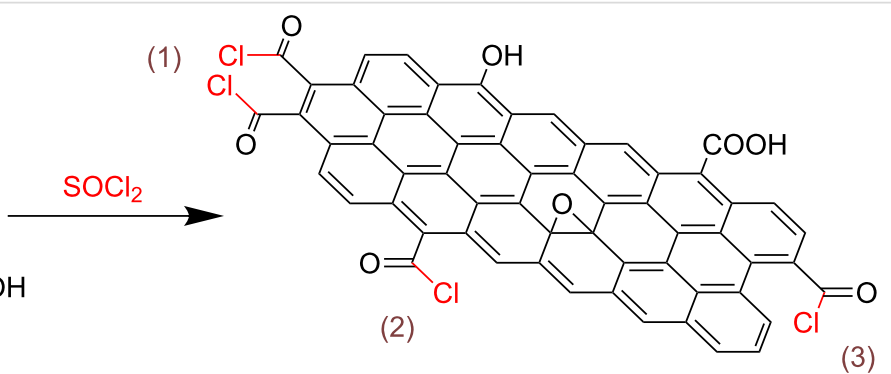

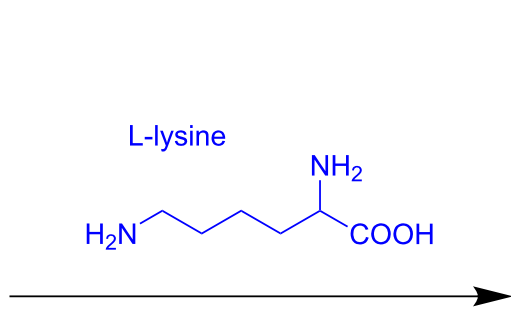

DMF, $90^{\circ} \mathrm{C}$
$\mathrm{HOOC}$

(1)

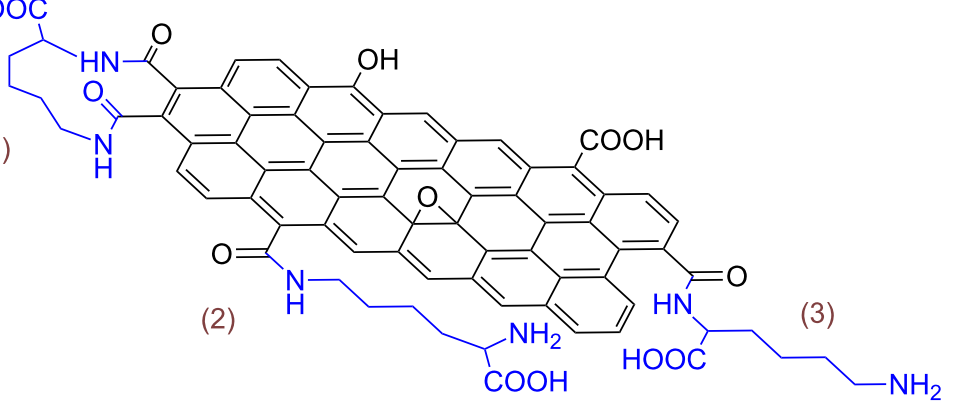

Scheme 1: Synthesis of Lys-GO. 
and technology project of Hebei province (no. 15214104D), and the National Natural Science Foundation of Hebei Education Department (no. QN2016088).

\section{References}

1. Wei, S.; Wu, R.; Jian, J.; Hou, J.; Chen, F.; Ablat, A.; Sun, Y. RSC Adv. 2015, 5, 40348-40351. doi:10.1039/C5RA01458A

2. Fan, H.-T.; Zhao, C.-Y.; Liu, S.; Shen, H. J. Chem. Eng. Data 2017, 62, 1099-1105. doi:10.1021/acs.jced.6b00918

3. Minitha, C. R.; Lalitha, M.; Jeyachandran, Y. L.; Senthilkumar, L.; Rajendra Kumar, R. T. Mater. Chem. Phys. 2017, 194, 243-252. doi:10.1016/j.matchemphys.2017.03.048

4. Wang, P.; He, F.; Wang, J.; Yu, H.; Zhao, L. Appl. Surf. Sci. 2015, 358, 175-180. doi:10.1016/j.apsusc.2015.06.102

5. Chen, D.; Zhang, H.; Liu, Y.; Li, J. Energy Environ. Sci. 2013, 6, 1362. doi:10.1039/c3ee23586f

6. Wang, J.; Chen, Z.; Chen, B. Environ. Sci. Technol. 2014, 48, 4817-4825. doi:10.1021/es405227u

7. Xu, C.; Yuan, Y.; Yuan, R.; Fu, X. RSC Adv. 2013, 3, 18002. doi:10.1039/c3ra42579g

8. Hung, Y.-H.; Su, C.-Y. Int. J. Hydrogen Energy 2017, 42, 22091-22099. doi:10.1016/j.ijhydene.2017.04.199

9. Gou, H.; He, J.; Mo, Z.; Wei, X.; Hu, R.; Wang, Y.; Guo, R. J. Electrochem. Soc. 2016, 163, B272-B279. doi:10.1149/2.0361607jes

10. Gupta, K.; Khatri, O. P. J. Colloid Interface Sci. 2017, 501, 11-21. doi:10.1016/j.jcis.2017.04.035

11. Ma, J.; Wang, X.; Liu, Y.; Wu, T.; Liu, Y.; Guo, Y.; Li, R.; Sun, X.; Wu, F.; Li, C.; Gao, J. J. Mater. Chem. A 2013, 1, 2192-2201. doi:10.1039/C2TA00340F

12. Li, J.; Wang, S.; Zhang, D.; Zhang, Q. High-performance hydrophilic PVDF/GO-lysine composite membrane. CN Pat. Appl. 105413494, March 23, 2016.

13. Chen, M.; Huo, C.; Li, Y.; Wang, J. ACS Sustainable Chem. Eng. 2016, 4, 1296-1302. doi:10.1021/acssuschemeng.5b01324

14. Zhao, F.; Dong, B.; Gao, R.; Su, G.; Liu, W.; Shi, L.; Xia, C.; Cao, L. Appl. Surf. Sci. 2015, 351, 303-308. doi:10.1016/j.apsusc.2015.05.121

15. Zhao, D.; Gao, X.; Wu, C.; Xie, R.; Feng, S.; Chen, C. Appl. Surf. Sci. 2016, 384, 1-9. doi:10.1016/j.apsusc.2016.05.022

16. Song, Y.; Cao, L.; Yu, J.; Zhang, S.; Chen, S.; Jiang, Y. J. Alloys Compd. 2017, 704, 245-253. doi:10.1016/j.jallcom.2017.01.310

17. Kumar, A. S. K.; Jiang, S.-J. J. Mol. Liq. 2017, 237, 387-401. doi:10.1016/j.molliq.2017.04.093

18. Long, M.; Qin, Y.; Chen, C.; Guo, X.; Tan, B.; Cai, W. J. Phys. Chem. C 2013, 117, 16734-16741. doi:10.1021/jp4058109

19. Luo, Q.-P.; Yu, X.-Y.; Lei, B.-X.; Chen, H.-Y.; Kuang, D.-B.; Su, C.-Y. J. Phys. Chem. C 2012, 116, 8111-8117. doi:10.1021/jp2113329

20. Zhang, C.; Wu, L.; Cai, D.; Zhang, C.; Wang, N.; Zhang, J.; Wu, Z. ACS Appl. Mater. Interfaces 2013, 5, 4783-4790. doi:10.1021/am4002666

21. Collins, W. R.; Schmois, E.; Swager, T. M. Chem. Commun. 2011, 47, 8790-8792. doi:10.1039/c1cc12829a

22. Shu, D.; Feng, F.; Han, H.; Ma, Z. Chem. Eng. J. 2017, 324, 1-9. doi:10.1016/j.cej.2017.04.136

23. Huang, Q.; Zhou, L.; Jiang, X.; Zhou, Y.; Fan, H.; Lang, W. ACS Appl. Mater. Interfaces 2014, 6, 13502-13509. doi:10.1021/am502586c
24. Zhou, L.; Yin, M.; Jiang, X.; Huang, Q.; Lang, W. New J. Chem. 2016, 40, 1454-1459. doi:10.1039/C5NJ02625C

25. Al-Ghouti, M. A.; Li, J.; Salamh, Y.; Al-Laqtah, N.; Walker, G.; Ahmad, M. N. M. J. Hazard. Mater. 2010, 176, 510-520. doi:10.1016/j.jhazmat.2009.11.059

26. Peng, W.; Li, H.; Liu, Y.; Song, S. J. Mol. Liq. 2016, 221, 82-87. doi:10.1016/j.molliq.2016.05.074

27. Fan, H.; Zhou, L.; Jiang, X.; Huang, Q.; Lang, W. Appl. Clay Sci. 2014, 95, 150-158. doi:10.1016/j.clay.2014.04.001

28. Chen, L.; Li, Y.; Du, Q.; Wang, Z.; Xia, Y.; Yedinak, E.; Lou, J.; Ci, L. Carbohydr. Polym. 2017, 155, 345-353. doi:10.1016/j.carbpol.2016.08.047

29. Li, Y.; Du, Q.; Liu, T.; Sun, J.; Wang, Y.; Wu, S.; Wang, Z.; Xia, Y.; Xia, L. Carbohydr. Polym. 2013, 95, 501-507. doi:10.1016/j.carbpol.2013.01.094

30. Heidarizad, M.; Şengör, S. S. J. Mol. Liq. 2016, 224, 607-617. doi:10.1016/j.molliq.2016.09.049

31. Yu, B.; Zhang, X.; Xie, J.; Wu, R.; Liu, X.; Li, H.; Chen, F.; Yang, H.; Ming, Z.; Yang, S.-T. Appl. Surf. Sci. 2015, 351, 765-771. doi:10.1016/j.apsusc.2015.05.185

32. Xie, X.; Xiong, H.; Zhang, Y.; Tong, Z.; Liao, A.; Qin, Z. J. Environ. Chem. Eng. 2017, 5, 2800-2806. doi:10.1016/j.jece.2017.05.024

33. Agcaoili, A. R.; Herrera, M. U.; Futalan, C. M.; Balela, M. D. L. J. Taiwan Inst. Chem. Eng. 2017, 78, 359-369. doi:10.1016/j.jtice.2017.06.038

34. Zhu, Q.; Wang, L.; An, Z.; Ye, H.; Feng, X. Appl. Surf. Sci. 2016, 371, 102-111. doi:10.1016/j.apsusc.2016.02.219

35. Tan, P.; Bi, Q.; Hu, Y.; Fang, Z.; Chen, Y.; Cheng, J. Appl. Surf. Sci. 2017, 423, 1141-1151. doi:10.1016/j.apsusc.2017.06.304

\section{License and Terms}

This is an Open Access article under the terms of the Creative Commons Attribution License (http://creativecommons.org/licenses/by/4.0), which permits unrestricted use, distribution, and reproduction in any medium, provided the original work is properly cited.

The license is subject to the Beilstein Journal of Nanotechnology terms and conditions: (http://www.beilstein-journals.org/bjnano)

The definitive version of this article is the electronic one which can be found at: $\underline{\text { doi:10.3762/bjnano.8.268 }}$ 